\title{
Cost-Effectiveness of Lactobacillus rhamnosus GG on the Prevention of Antibiotic-Associated Diarrhea in Children in Colombia
}

\author{
Renata Nahuys Tebyriçá Prioli' ${ }^{*}$, Mayra Lemos², Teresa Lemmer² \\ ${ }^{1}$ Procter\&Gamble Industrial e Comercial LTDA, Av. Doutor Chucri Zaidan, 296, $24^{\circ}$ a $27^{\circ}$ andares e Mezanino, \\ conjuntos 241 a 271, Vila Cordeiro São Paulo - SP, 04583-110, São Paulo, Brazil \\ ${ }^{2}$ Kantar, Health Division, Av. Francisco Matarazzo, 1350, 5th floor, 05001-100, São Paulo, Brazil
}

Received Date: August 05, 2020; Accepted Date: August 28, 2020; Published Date: September 08, 2020

"Corresponding contact: Priscila Nitta on behalf of Renata Prioli, Procter \& Gamble Industrial e Comercial LTDA, Av. Doutor Chucri Zaidan, 296, 24 a $27^{\circ}$ andares e Mezanino, conjuntos 241 a 271, Vila Cordeiro São Paulo - SP, 04583-110, São Paulo, Brazil. Email: nitta.p@pg.com

\section{Abstract}

Objective: Antibiotic-associated diarrhea (AAD) is a common complication of systemic antibiotic treatment. AAD is associated with extra investigations and treatment and additional nursing care, thus leading to higher costs. Lactobacillus rhamnosus GG (LGG) is a probiotic that has been showing to reduce the risk of AAD in children. The objective of this study is to evaluate the cost-effectiveness of LGG for preventing $\mathrm{AAD}$ in children in Colombia, from private hospital's perspective.

Methods: It was developed a decision tree using Microsoft Excel to simulate the clinical course of a patient in antibiotic treatment. The population assessed was pediatric patients receiving antibiotic therapy during hospitalization. The data on efficacy, effectiveness, use of resources, and costs were obtained from literature review. It was considered the cost of one sachet as 4,947.97 Colombian pesos (COP), obtained from Colombian drugstore websites. In the model, it was used a duration of two days minimum AAD for both LGG and placebo arms. Only direct expenses were considered to estimate the cost of treatment with LGG compared with placebo. A deterministic sensitivity analysis was performed to measure the robustness of the model.

Results: In the base case scenario, the use of LGG for treating $\mathrm{AAD}$ in pediatric patients was less costly when compared with placebo or no additional intervention: 45,820.11 COP versus 76,093.97 COP, respectively, representing a dominating incremental cost-effectiveness ratio (ICER) of $-225,924.37$ COP/AAD avoided. The deterministic sensitivity analysis showed that the main costs were the length of hospital stay with placebo or no additional prophylactic therapy, the length of hospital stay with LGG prophylactic therapy, and the duration of antibiotic therapy.

Conclusion: Based on a Colombian private hospital's perspective, the use of LGG as prophylactic therapy for AAD in pediatric inpatients, during antibiotic therapy, was more effective and less costly compared with placebo or no additional intervention.

Keywords: Antibiotic-Associated Diarrhea; Colombia; CostEffectiveness; Diarrhea Prevention \& Control; Dysbiosis; Health Economics; Lactobacillus Rhamnosus GG; Microbiota; Preventive Medicine; Private Hospital's Perspective; Probiotics

\section{Introduction}

Diarrhea is a common complication of systemic antibiotic treatment, which. It can cause fluid loss and lead to dehydration, and if not treated properly, it can have serious adverse events. Antibiotic-associated diarrhea (AAD), emerging as a frequent reaction of antibiotic use, is defined as unexplained diarrhea that occurs in association with the administration of antibiotics [1].

The incidence of AAD in the pediatric population is 5$30 \%$, and in adults, $5-70 \%$, depending on the type of antibiotic, 
host factors such as age, health status, etiology, hospitalization status and presence of nosocomial outbreak [1-3]. In AAD patients in Colombian hospital symptoms as abdominal pain and bloating, fever, tachycardia have been found, as well as the longer hospital stay [4].

In most cases of $\mathrm{AAD}$, no infectious agent is found. Despite this, Clostridium difficile is responsible for the most severe cases (Clostridium difficile-associated diarrhea - CDAD) [1, 2], which may lead to electrolyte disturbances, pseudomembranous colitis, toxic megacolon and, rarely, death $[\mathbf{1 , 5}]$.

Managing diarrhea depends on the clinical presentation and the inciting agent. In mild to moderate diarrhea, conventional measures include rehydration or discontinuation of the inciting agent or its replacement by an antibiotic with a lower risk of inducing diarrhea [6]. More severe cases often require bed rest, intravenous fluids, and additional antibiotics such as metronidazole or vancomycin [1, 5]. As an option, probiotic products have been proposed as a preventive measure to avoid AAD, based on the hypothesis that dysbiosis related to antibiotic use triggers ADD, and these interventions may contribute to an unbalanced gastrointestinal flora normalization.

Probiotics are defined as "living microorganisms which, when administered in adequate amounts, confer a health benefit on the host" [7]. Some of the proposed mechanisms are stimulation of immunity system, competition for nutrients, inhibition of pathogens mucosal adherence and epithelial invasion, as well as the production of antimicrobial substances
[8]. In this scenario, Lactobacillus rhamnosus $G G$ (LGG) is a probiotic that has shown reduce of AAD risk in children [2].

So far, AAD was associated with additional medical resource use, leading to higher costs [9]. Studies demonstrated that, in patients whose hospital stay was complicated by diarrhea caused by $C$. difficile, adjusted hospital costs were $54 \%$ (95\% confidence interval [CI]: 17\%-103\%) higher when compared with patients without this complication [10]. Economic evaluations have been demonstrating that the use of probiotics for prophylaxis for AAD would lead to estimated savings in direct medical costs [11-13]. However, no economic evaluations specific for LGG or in a Colombian context were found.

Therefore, this study aims to evaluate the cost-effectiveness of LGG for the prevention of AAD in children in Colombia, from the private hospital's perspective.

\section{Methods}

\section{Model description}

We developed a decision tree (Figure 1) using Microsoft Excel to simulate the clinical course of a patient in antibiotic treatment, and thus to investigate the costs and effects of LGG for preventing AAD during antibiotic therapy in hospitalized children. The decision tree started with hospitalized pediatric patients on antibiotic treatment, who were using or not LGG for the prevention of AAD. For each case, patients could develop AAD or don't develop any diarrhea.

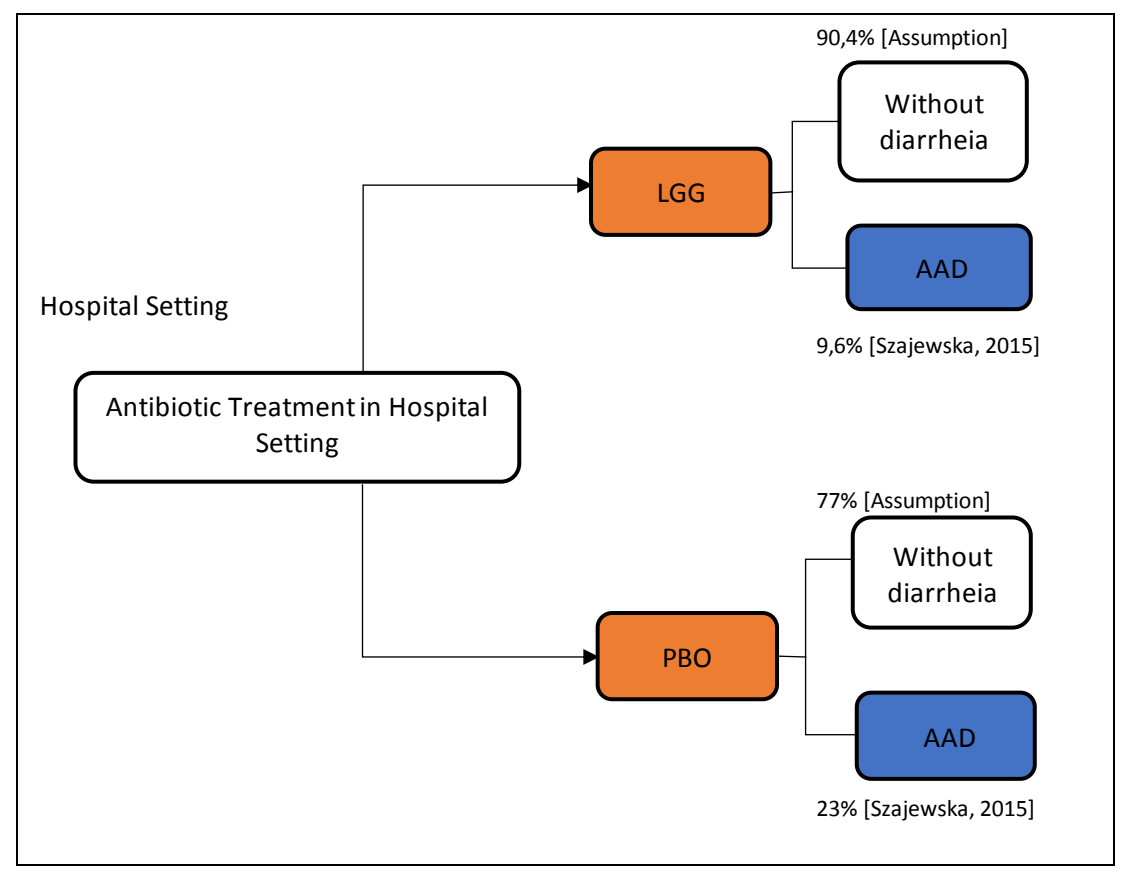

Figure 1: Decision model structure. 


\section{Model parameters}

\section{Efficacy}

Data on efficacy, effectiveness, use of resources, and costs were obtained from a literature review and additional researches in the literature. We searched the Medical Literature Analysis and Retrieval System Online (MEDLINE), Virtual Health Library (VHL), and the International Society for Pharmacoeconomics and Outcomes Research (ISPOR) Scientific Presentations databases until June 4th, 2019. Also, we conducted additional searches on health technology assessment agencies such as the National Institute for Health and Care Excellence (NICE), Canadian Agency for Drugs and Technologies in Health (CADTH), Pharmaceutical Benefits Scheme (PBS), and Institute for Clinical and Economic Review (ICER). The data on the risk of developing AAD in hospitalized children was obtained from the systematic review with meta-analysis published by Szajewska and Kołodziej (2015). According to the results reported, the risk of AAD with LGG as a prophylaxis therapy was $9.6 \%$, compared with $23 \%$ with placebo or no additional intervention during antibiotic therapy [2].

\section{Costs}

LGG costs were obtained considering the use of two sachets (dose of $1 \times 10^{10} \mathrm{CFU}$ ) per day of antibiotic therapy. This number of sachets was used since evidence suggested that the best effect in children was achieved with the highest daily dose (1-2 x 10 $\left.{ }^{10} \mathrm{CFU}\right)$ [2], and a specialist confirmed that the dose of $1 \times 10^{10} \mathrm{CFU}$ is the commonly used for prophylaxis therapy in the clinical practice. We considered the mean cost of one sachet as 4,947.97 Colombian pesos (COP), obtained from Colombian drugstore websites [14-17]. Only direct costs were considered to estimate the cost of treatment with LGG compared with placebo, including the use of pharmacological resources (LGG or no treatment) related to the prophylaxis therapy and disease management (hospitalization costs). Hospitalization costs included the length of hospital stay in days, which we assumed was equal to the duration of AAD. We used a minimum AAD duration of two days for both LGG and placebo arms [18]. The cost per bed day in a tertiary level hospital was 76,235.59 COP in 2005, according to the World Health Organization (WHO) estimate [19]. This value corresponds to $136,196.24$ COP in 2019 after a mean annual inflation adjustment of $4.23 \%$ [20].

\section{Deterministic sensitivity analysis}

A deterministic sensitivity analysis was performed to measure the robustness of the model. It was included for all inputs in the model. The results were reported graphically in a tornado plot, considering different upper and lower values, revealing which factors had the most significant effect on the base case variability. (Table 1) shows the minimum and maximum values considered in the analysis.

\begin{tabular}{|c|c|c|c|c|}
\hline Parameter & Minimum & Base case & Maximum & $\begin{array}{l}\text { Data variation source } \\
\text { (Min, Max) }\end{array}$ \\
\hline Risk of AAD - LGG & $6.0 \%$ & $9.6 \%$ & $11 \%$ & $\begin{array}{l}\text { Sjazewska et al., } 2009 \text { [18] (Min); } \\
\text { Assumption } \pm 10 \% \text { (Max) }\end{array}$ \\
\hline Risk of AAD - Placebo & $20.0 \%$ & $23.0 \%$ & $25 \%$ & $\begin{array}{c}\text { Sjazewska et al., } 2009[\mathbf{1 8}](\text { Min); } \\
\text { Assumption } \pm 10 \% \text { (Max) }\end{array}$ \\
\hline LGG - Cost of 1 sachet & $\begin{array}{c}\mathrm{COP} \\
4,453.17\end{array}$ & $\begin{array}{c}\text { COP } \\
4,947.97\end{array}$ & $\begin{array}{c}\mathrm{COP} \\
5,442.77\end{array}$ & Assumption $\pm 10 \%$ \\
\hline Hospital stay - AAD patients - LGG & 2.00 & 3.00 & 8.00 & Elseviers et al., 2015 [9] \\
\hline Hospital stay - AAD patients - Placebo & 2 & 2.43 & 8.00 & Elseviers et al., 2015 [9] \\
\hline Number of sachets & 2.00 & 2.00 & 4.00 & Sjazewska et al., 2015 [2] \\
\hline Cost per bed day & $\begin{array}{c}\text { COP } \\
122,576.62\end{array}$ & $\begin{array}{c}\text { COP } \\
136,196.24\end{array}$ & $\begin{array}{c}\text { COP } \\
149,815.86\end{array}$ & Assumption $\pm 10 \%$ \\
\hline $\begin{array}{c}\text { Total Cost of Hospital stay - AAD patients } \\
\text { - LGG }\end{array}$ & $\begin{array}{c}\text { COP } \\
367,219.11\end{array}$ & $\begin{array}{c}\text { COP } \\
408,021.24\end{array}$ & $\begin{array}{c}\text { COP } \\
448,823.36\end{array}$ & Assumption $\pm 10 \%$ \\
\hline $\begin{array}{c}\text { Total Cost of Hospital stay - AAD patients } \\
\text { - Placebo }\end{array}$ & $\begin{array}{c}\text { COP } \\
297,759.03\end{array}$ & $\begin{array}{c}\text { COP } \\
330,843.37\end{array}$ & $\begin{array}{c}\text { COP } \\
363,927.70\end{array}$ & Assumption $\pm 10 \%$ \\
\hline Duration of antibiotic therapy (days) & 2.00 & 7.00 & 41.00 & Elseviers et al., 2015 [9] \\
\hline
\end{tabular}

Table 1: Deterministic Sensitivity Analysis Parameters. 


\section{Assumptions and Limitations}

Since there is a lack of published evidence regarding preventing AAD in hospitalized children with LGG, we had to make some assumptions in the model. Thus, we conducted two scenarios with LGG data on AAD treatment/ prevention: a base case scenario, with inpatient pediatric patients (based on Guandalini et al., 2000 [19]) and an alternative scenario with inpatient adult patients (based on Thomas et al., 2001[20]). Also, there was no data regarding length of hospitalization stay in studies that assessed LGG for preventing AAD in inpatient pediatric patients (e.g., Szajewska et al., 2009 [18]). Due to this limitation, we performed an alternative scenario analysis considering the length of stay data published for adult patients by Thomas et al., 2001 [20].

\section{Results}

\section{Base Case Analysis}

In the base case scenario, the use of LGG for treating AAD in inpatient pediatric patients was less costly when compared with placebo or no additional intervention: 45.820,11 COP versus 76,093.97 COP, respectively. Thus, the incremental cost of LGG concerning placebo or no additional intervention was $-30,273.87 \mathrm{COP}$, representing a dominating incremental cost-effectiveness ratio (ICER) of -225.924,37 COP/AAD avoided. (Table 2) presents the total costs of LGG and placebo.

\begin{tabular}{|c|c|}
\hline Intervention & Total costs \\
\hline LGG & $45,820.11 \mathrm{COP}$ \\
\hline Placebo & $76,093.97 \mathrm{COP}$ \\
\hline \multicolumn{2}{|c|}{ LGG, Lactobacillus rhamnosus $\mathbf{G G}$} \\
\hline
\end{tabular}

Table 2: Total costs of intervention and of each comparator.

\subsection{Alternative Scenario}

In the alternative scenario, LGG would also be less costly regarding placebo or no additional intervention for preventing AAD in inpatient adult patients: 77,986.80 COP versus $134,698.08$ COP, respectively. Thus, the incremental cost of LGG concerning placebo or no additional intervention was 56,711.28 COP, representing a dominating ICER of 423,218.53 COP/AAD avoided. (Table 3) shows the total costs of LGG and placebo.

\begin{tabular}{|c|c|}
\hline Intervention & Total costs \\
\hline LGG & $77,986.80$ COP \\
\hline Placebo & $134,698.08$ COP \\
\hline \multicolumn{2}{|c|}{ LGG, Lactobacillus rhamnosus GG } \\
\hline
\end{tabular}

Table 3: Total costs of intervention and of each comparator.

\section{Deterministic Sensitivity Analysis}

The most sensitive parameters were the length of hospital stay with placebo or no additional prophylactic therapy, length of hospital stay with LGG prophylactic therapy, duration of antibiotic therapy, and LGG cost of 1 sachet (Figure 2). (Table 4) depicts the parameters assessed in the deterministic sensitivity analysis and the ICER results related to these parameters changes.

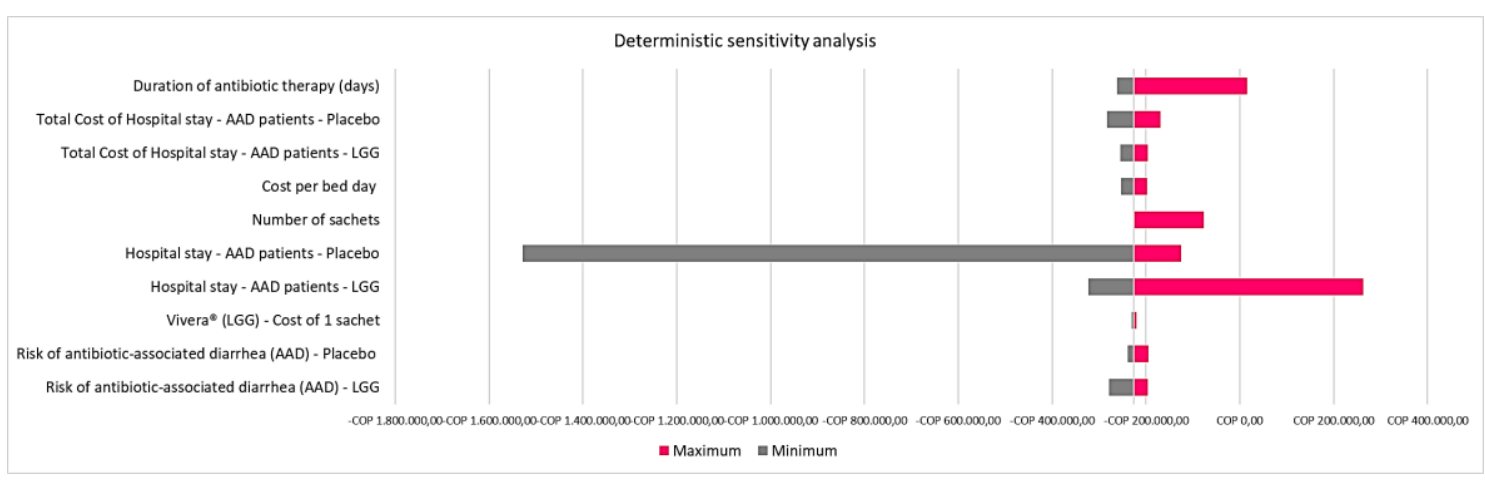

Figure 2: Minimum and maximum ICER results of deterministic sensitivity analysis for each parameter used. 


\begin{tabular}{|c|c|c|c|}
\hline Parameter & Minimum & Base case & Maximum \\
\hline Risk of AAD - LGG & - 279,155.33 COP & - 225,924.37 COP & - 196,598.05 COP \\
\hline Risk of AAD - Placebo & $-239,550.21 \mathrm{COP}$ & - 225,924.37 COP & - 195,659.28 COP \\
\hline LGG - Cost of 1 sachet & $-230,887.13 \mathrm{COP}$ & - 225,924.37 COP & - 220,961.59 COP \\
\hline Hospital stay - AAD patients - LGG & $-323,091.24 \mathrm{COP}$ & $-225,924.37 \mathrm{COP}$ & $262,349.31 \mathrm{COP}$ \\
\hline Hospital stay - AAD patients - Placebo & $-1,528,216.22 \mathrm{COP}$ & - 225,924.37 COP & $-125,598.22 \mathrm{COP}$ \\
\hline Number of sachets & $-225,924.37 \mathrm{COP}$ & - 225,924.37 COP & - 77,042.21 COP \\
\hline Cost per bed day & $-253,479.54 \mathrm{COP}$ & - 225,924.37 COP & - 198,369.20 COP \\
\hline $\begin{array}{c}\text { Total Cost of Hospital stay - AAD patients } \\
\text { - LGG }\end{array}$ & $-255,155.74 \mathrm{COP}$ & $-225,924.37 \mathrm{COP}$ & - 196,693.00 COP \\
\hline $\begin{array}{c}\text { Total Cost of Hospital stay - AAD patients } \\
\text { - Placebo }\end{array}$ & - 282,710.91 COP & - 225,924.37 COP & $-169,137.82 \mathrm{COP}$ \\
\hline Duration of antibiotic therapy (days) & $-261,372.50 \mathrm{COP}$ & - 225,924.37 COP & $15,122.94 \mathrm{COP}$ \\
\hline
\end{tabular}

Table 4: Parameters analyzed in the deterministic sensitivity analysis of the model.

\section{Discussion}

This cost-effectiveness analysis showed that LGG was cost-saving in all scenarios. In the base case, the use of LGG would save -102,636.28 COP (-31.37 USD) per AAD avoided in hospitalized pediatric patients. The results were based on a daily dose of $1 \times 10^{10} \mathrm{CFU}$ during antibiotic therapy for any etiology - the LGG dose with higher efficacy based on literature, and following a real clinical practice based on specialist opinion [2]. LGG significant efficacy on preventing AAD in inpatient children was an essential determinant of cost-effectiveness since other clinical (e.g., duration of antibiotic therapy and length of hospital stay) and economic parameters (e.g., LGG and bed day costs) were similar between both arms analyzed.

Although there is a lack of literature evidence assessing the cost-effectiveness of LGG use for preventing AAD in inpatient children, we found two prior cost-benefit analyses regarding other probiotics for prophylaxis of AAD. One of these studies estimated the consequences in the direct medical costs that might result from the use of a probiotic formula for the prophylaxis of AAD and CDAD in a North American context. The authors found that the use of the probiotic formula would result in estimated mean savings of 1,968 USD per patient for the single-dose and 2,661 USD per patient for the double dose compared with placebo if used in an average of 13 days by all patients at risk of developing AAD and CDAD [11]. Another study assessed the cost-effectiveness of probiotic use for the prevention of $C$. difficile infection (CDI) versus no probiotic use, also in a North American context. The authors considered specific probiotic formulations, based on the findings in the meta-analysis subgroups. The results showed that in the base case, probiotics dominated over no probiotics. However, probiotics had an unfavorable incremental cost-effectiveness ratio (ICER) of 1.26 USD million/QALY in the worst-case scenario [12].

A deterministic sensitivity analysis was performed to assess the reliability and robustness of LGG cost-savings results in the base case scenario. Even considering a higher dose or higher costs for treatment, the probiotic use dominated (it was more effective and less costly) concerning no probiotic use. The only scenario in which LGG use was not dominant considered a longer length of hospital stay, although it represented an incremental cost of only 15,122.94 COP (4.62 USD).

AAD patients present a high frequency of severe comorbidities, like abdominal pain and bloating, fever and tachycardia, as well as more extended hospital stay (median of 10 days, ranging from 2 to 104 days). Evidence suggests that gastroenteritis events can lead to substantial morbidity, mortality, and healthcare system costs in Latin America countries. Comparing with literature evidence, Colombian patients were considered younger (58 versus 71.9 years) and received a shorted antibiotic treatment regimen (4.9 versus 7 days) [23]. Also, it has been demonstrated that productivity losses associated with rotavirus gastroenteritis contributed to economic burden to health systems in Latin American and 
Caribbean countries [24]. Thus, this study results can be substantial in the management of AAD in Colombia [24].

There were some limitations to this model. No length of hospital stay data for inpatients children receiving LGG as prophylactic therapy was found. As we found no data specifically for children, we assumed that this parameter would be like the duration of AAD, based on the published literature on an outpatient setting. Direct medical costs (bed day) were based in 2005 Colombian pesos, and these costs were correct using the historical inflation rate of Colombia. Finally, although indirect costs contribute to the economic burden of the disease, they were not considered in this costeffectiveness model.

\section{Conclusion}

The current model demonstrated that, based on a Colombia payers' perspective, the use of LGG as prophylactic therapy for AAD in pediatric inpatients, during antibiotic therapy, was more effective and less costly compared with placebo or no additional intervention. Therefore, health policy decisionmakers should consider prioritizing funding oral probiotics among patients with AAD.

\section{Competing interests}

Teresa Lemmer is an employee of Kantar - Health Division and Diego Kashiura and Elene Nardi are former employees at Kantar - Health Division, which was hired by Procter \& Gamble Industrial e Commercial LTDA develop the study. Hector Daniel Cuelo Romero is an employee of Procter \& Gamble Industrial e Commercial LTDA and Renata Nahuys Tebyriçá Prioli is a former employee of Procter \& Gamble Industrial e Commercial LTDA which funded the study.

\section{Acknowledgement and Funding}

This study was funded by Procter \& Gamble Industrial e Commercial LTDA

\section{References}

1. Bartlett JG (2002) Clinical practice. Antibioticassociated diarrhea. N Eng J Med 346:334-339.

2. Szajewska H, Kolodziej M (2015) Systematic review with meta-analysis: Lactobacillus rhamnosus GG in the prevention of antibiotic-associated diarrhoea in children and adults. Aliment Pharmacol Ther 42:1149-1157.

3. McFarland LV (2008) Antibiotic-associated diarrhea: epidemiology, trends and treatment. Future Microbiol 3:563-578.
4. Rodríguez - Varón A, Muñoz O, Pulido-Arenas J, Amado S, Tobón - Trujillo M (2017) Antibioticassociated diarrhea: Clinical characteristics and the presence of Clostridium difficile. Revista de Gastroenterología de México (English Edition) 82:129133.

5. Nelson RL, Suda KJ, Evans CT (2017) Antibiotic treatment for Clostridium difficile-associated diarrhoea in adults. Cochrane Database Syst Rev 3:CD004610.

6. Barbut F, Meynard JL (2002) Managing antibiotic associated diarrhoea. BMJ 324:1345-1346.

7. Hill C, Guarner F, Reid G, Gibson GR, Merenstein DJ, et al. (2014) Expert consensus document. The International Scientific Association for Probiotics and Prebiotics consensus statement on the scope and appropriate use of the term probiotic. Nat Rev Gastroenterol Hepatol 11:506-514.

8. Rolfe RD (2000) The role of probiotic cultures in the control of gastrointestinal health. J Nutr 130:396S$402 \mathrm{~S}$.

9. Elseviers MM, Van Camp Y, Nayaert S, Dure K, Annemans L et al. (2015) Prevalence and management of antibiotic associated diarrhea in general hospitals. BMC Infect Dis 15:129.

10. Kyne L, Hamel MB, Polavaram R, Kelly CP (2002) Health care costs and mortality associated with nosocomial diarrhea due to Clostridium difficile. Clin Infect Dis 34:346-353.

11. Kamdeu Fansi AA, Guertin JR, LeLorier J (2012) Savings from the use of a probiotic formula in the prophylaxis of antibiotic-associated diarrhea. J Med Econ 15:53-60.

12. Shen NT, Leff JA, Schneider Y, Crawford CV, Maw A et al. (2017) CostEffectiveness Analysis of Probiotic Use to Prevent Clostridium difficile Infection in Hospitalized Adults Receiving Antibiotics. Open Forum Infect Dis 4:ofx148.

13. Li N, Zheng B, Cai HF, Chen YH, Qiu MQ et al. (2018) Cost-effectiveness analysis of oral probiotics for the prevention of Clostridium difficile-associated diarrhoea in children and adolescents. J Hosp Infect 99:469-474.

14. Droguerias Cafam. Vivera Suplemento Dietario Caja Con 8 Sobres Con 2 g C/U 2018 [Available from: https://www.drogueriascafam.com.co/cuidadodigestivo/8870-comprar-en-cafam-vivera-caja-con8-sobres-suplemento-precio-4054839015915.html.

15. Farmalisto Colombia. Vivera Caja Con 8 Sobres 2018 [Available from: 
https://www.farmalisto.com.co/drogueriafarmacia/37134-comprar-vivera-caja-con-8-sobresprecio-4054839015915.html.

16. Larebaja. Vivera 2018 [Available from: https://www.larebajavirtual.com/catalogo/producto/p roducto/110480/descripcion/VIVERA.html.

17. Locatel Colombia. Vivera caja X 8 sobres 2018 [Available from:

https://www.locatelcolombia.com/medicamentosprescripcion-aparato-digestivo-vivera/p.Szajewska H, Albrecht P, Topczewska-Cabanek A (2009) Randomized, double-blind, placebo-controlled trial: effect of lactobacillus GG supplementation on Helicobacter pylori eradication rates and side effects during treatment in children. J Pediatr Gastroenterol Nutr 48:431-436.

18. Guandalini S, Pensabene L, Zikri MA, Dias JA, Casali LG et al. (2000) Lactobacillus GG administered in oral rehydration solution to children with acute diarrhea: a multicenter European trial. J Pediatr Gastroenterol Nutr 30:54-60.

19. Thomas MR, Litin SC, Osmon DR, Corr AP, Weaver AL et al. (2001) Lack of effect of Lactobacillus GG on antibiotic-associated diarrhea: a randomized, placebo-controlled trial. Mayo Clin Proc 76:883-889.

20. Rodriguez-Varon A, Munoz OM, Pulido-Arenas J, Amado SB, Tobon-Trujillo M (2017) Antibioticassociated diarrhea: Clinical characteristics and the presence of Clostridium difficile. Rev Gastroenterol Mex 82:129-133.

21. Rheingans $\mathrm{RD}$, Constenla $\mathrm{D}$, Antil L, Innis BL, Breuer T (2007) Economic and health burden of rotavirus gastroenteritis for the 2003 birth cohort in eight Latin American and Caribbean countries. Rev Panam Salud Publica 21:192-204.

Citation: Nitta P, Prioli RNT, Lemos M, Lemmer T (2020) Cost-Effectiveness of Lactobacillus rhamnosus GG on the Prevention of Antibiotic-Associated Diarrhea in Children in Colombia. Adv in Nutri and Food Sci: ANAFS-192 